\title{
2 Loss of locus coeruleus noradrenergic neurons alters 3 the inflammatory response to LPS in substantia nigra but does 4 not affect nigral cell loss
}

5 Mahmoud M. Iravani • Mona Sadeghian •

6 Sarah Rose $\cdot$ Peter Jenner

7 Received: 4 December 2013/ Accepted: 12 April 2014

8 (C) Springer-Verlag Wien 2014

AQ1 Abstract In Parkinson's disease (PD), destruction of 10

11

12

13

14

15

16

17

18

19 noradrenergic neurons in the locus coeruleus (LC) may precede damage to nigral cells and subsequently exaggerate dopaminergic cell loss. We examine if destruction of the locus coeruleus with $N$-(2-chloroethyl)- $N$-ethyl-2-bromobenzylamine (DSP-4) alters dopaminergic cell loss in substantia nigra (SN) initiated by lipopolysaccharide (LPS) in the rat through an effect on glial cell activation. In rats, a single intraperitoneal dose of DSP-4 administered 8 days previously, caused a marked loss of tyrosine hydroxylase positive neurons in LC but no change in dopaminergic cell number in SN. Unilateral nigral LPS administration resulted in marked dopaminergic cell death with reactive microgliosis associated with enhanced $\mathrm{p} 47_{\text {phox }}$ in OX-6 and OX-42 positive microglia. There was proliferation of inducible nitric oxide synthase (iNOS)-positive cells, formation of 3-nitrotyrosine (3-NT) and proliferation of astrocytes that expressed glial cell line-derived neurotrophic factor (GDNF). Following combined DSP-4 treatment and subsequent administration of LPS, unexpectedly, no further loss of tyrosine hydroxylase (TH)-immunoreactivity (-ir) occurred in the SN compared to the effects of LPS alone. However, there was a marked alteration in the morphology of microglial cell and a reduction of 3-NTand iNOS-ir was evident. Expression of $\mathrm{p} 47_{\text {phox }}$ was downregulated in microglia but up-regulated in $\mathrm{TH}$-ir

M. M. Iravani $(\bowtie) \cdot$ M. Sadeghian $\cdot$ S. Rose $\cdot$ P. Jenner Neurodegenerative Diseases Research Group, Institute of Pharmaceutical Sciences, School of Biomedical Sciences, King's College London, London, UK

e-mail: m.iravani@kcl.ac.uk; m.iravani@herts.ac.uk

M. M. Iravani

School of Life and Medical Sciences, University of Hertfordshire, Hatfield, UK neurons. No further change in GFAP-ir was observed compared to that produced by DSP-4 alone or LPS alone, but the expression of GDNF was markedly reduced. This study suggests that in contrast to previous reports, prior LC damage does not influence subsequent nigral dopaminergic cell degeneration induced by LPS. Rather it appears to attenuate the microglial response thought to contribute to disease progression in PD.

Keywords Astrocytosis - Dopamine - DSP-4 ( $N$-(2-chloroethyl)- $N$-ethyl-2-bromobenzylamine) · Lipopolysaccharide · Locus coeruleus · Microgliosis · Noradrenaline · Parkinson's disease · p4 $7_{\text {phox }}$. Substantia nigra

\section{Introduction}

Noradrenergic neurons arising from the locus coeruleus (LC) degenerate with Lewy body pathology in Parkinson's disease (PD) leading to a decrease in mid- and fore-brain noradrenaline content (German et al. 1992; Forno et al. 1993; del Tredici et al. 2002; Braak et al. 2003). Noradrenergic fibres activate $\alpha$-adrenergic receptors located on dopaminergic neurons in substantia nigra (SN) and stimulation of the LC facilitates their burst firing (Grenhoff et al. 1993). However, the degeneration of LC noradrenergic neurons in PD may precede the loss of dopaminergic cells in SN and it has been suggested that LC loss influences the rate of SN loss $\mathbf{A Q 2} 0$ (del Tredici and Braak 2013). For example, in non-human primates and mice damage to the nigrostriatal pathway induced by 1-methyl-4-phenyl-1,2,3,6-tetrahydropyridine (MPTP) was potentiated by prior destruction of the locus coeruleus using the selective noradrenergic neurone toxin, $N$-(2-chloroethyl)- $N$-ethyl-2-bromobenzylamine (DSP-4) 
(Mavridis et al. 1991; Fornai et al. 1996). In reverse, pharmacological or genetic blockade of the noradrenaline transporter protected nigrostriatal dopaminergic neurons from MPTP toxicity in mice (Rommelfanger et al. 2004). But how this protective effect is mediated remains unknown.

One possibility is that the noradrenergic input from the LC influences glial-mediated changes in the $\mathrm{SN}$ and reduces processes such as oxidative and nitrative stress that are associated with the progression of dopaminergic cell death in PD. Indeed, noradrenaline binds to $\alpha$ - and $\beta$-adrenoceptors located on astrocytes and glia to regulate the expression of the inflammatory factors, tumour necrosis factor- $\alpha$ and interleukin- $1 \beta$ (Feinstein et al. 2002; Heneka et al. 2003; Heneka and Landreth 2007; Pugh et al. 2007) and alters the expression of inducible NO synthase (iNOS) and NO production (Chang and Liu 2000). In addition, noradrenaline can protect dopaminergic neurons against glial-induced oxidative stress (Troadec et al. 2001).

Lipopolysaccharide (LPS) is used to induce activation of microglial cells and astrocytes and the loss of dopaminergic neurons in the SN (Castano et al. 1998; Herrera et al. 2000, Iravani et al. 2002, 2005, 2008). So, we now investigate the possibility that a prior LC lesion will influence its action. We have compared the effects of direct supra-nigral administration of LPS alone to induce inflammation and nigral cell loss and the effects observed in combination with DSP-4 mediated destruction of the LC.

\section{Experimental procedures}

Experimental animals

All animal experiments were conducted according to guidelines set out in the UK Animals (Scientific Procedures) Act 1986 and were approved by a local ethical committee at King's College London. All animals had unrestricted access to food and water and were kept at a 12-h light: 12-h dark cycle. In two groups of male Wistar rats $(250-300 \mathrm{~g})$, either a single normal saline $(1 \mathrm{ml} / \mathrm{kg}$, i.p., $n=10$ ) or a single dose of $N$-(2-chloroethyl)- $N$-ethyl2-bromobenzylamine [dissolved in sterile water as the quantity of DSP-4 used was not fully soluble in $0.9 \%$ saline (DSP-4; $50 \mathrm{mg} / \mathrm{kg}$ i.p., $n=14$; Sigma-Aldrich, Poole, UK)] was administered. A single $50 \mathrm{mg} / \mathrm{kg}$ i.p. dose of DSP-4 leads to profound loss of noradrenaline (80 and $50 \%$ loss in the cortex and the substantia nigra, respectively) within 3 days (Fornai et al. 1997).

\section{Stereotaxic surgery}

One week following administration of saline or DSP-4, on day eight, animals were anaesthetised with a mixture of isoflurane (3-5 \% for induction, $1-1.5 \%$ for maintenance) and $95 \% \mathrm{O}_{2}, 5 \% \mathrm{CO}_{2}$. While maintained under isoflurane anaesthesia, rats were placed in a Kopf stereotaxic frame (Tijunga, USA) with the incisor bar set at $-3.3 \mathrm{~mm}$. Body temperature was measured using a rectal probe and maintained at $37 \pm 1{ }^{\circ} \mathrm{C}$ using a thermostatic heating blanket underlying the animal.

The saline-treated animals were supra-nigrally administered with $2 \mu \mathrm{l}$ filter-sterile $0.1 \mathrm{M}$ phosphate-buffered saline (PBS, pH 7.4;n=4) or LPS (Calbiochem, c/o Merck, Darmstadt, Germany, serotype 055:B5, E. coli; $n=8$ ) dissolved at a concentration of $2 \mu \mathrm{g} / \mu \mathrm{l}$ in a volume of $2 \mu \mathrm{l}$ (total dose, $4 \mu \mathrm{g}$ ). The DSP-4 treated animals were also treated supra-nigrally with $4 \mu \mathrm{g} \operatorname{LPS}(n=8)$. The following stereotaxic co-ordinates were used: AP, $-4.8 \mathrm{~mm}$; L, $2.0 \mathrm{~mm}$; V, $-7.6 \mathrm{~mm}$. This location corresponded to the largest segment of SN in the coronal plane (Paxinos and Watson 1986). All nigral administrations were carried out using a 5- $\mu$ l Hamilton syringe for a period of 2 min using a Kopf series 5000 microinjector in accord with a previously used protocol (Iravani et al. 2008). The remaining DSP-4 treated rats were used as DSP-4 controls.

Immunohistochemistry

Tyrosine hydroxylase (TH) immunoreactivity was assessed in the LC and SN as a marker of noradrenergic and dopaminergic neurons, respectively. GFAP and OX-6 and OX-42 immunoreactivity were used as markers of astrocyte and microglial activation. Expression of iNOS and 3-nitrotyrosine (3-NT), immunoreactivity was used to assess nitrative stress in the SN. P47 phox immunoreactivity was used as a marker of NADPH-oxidase activation and superoxide formation.

At $24 \mathrm{~h}$ following supra-nigral PBS or LPS administration, animals were euthanised by $\mathrm{CO}_{2}$ exposure until breathing completely stopped. The thoracic cavity was quickly opened; animals were intra-cardially perfused with $0.1 \mathrm{M} \mathrm{PBS}, \mathrm{pH} 7.4$ at $4^{\circ} \mathrm{C}$ followed by phosphate-buffered $4 \%$ paraformaldehyde solution. Directly after perfusion, the brains were removed, post fixed for a further $48 \mathrm{~h}$, washed in $0.1 \mathrm{M}$ PBS, and cryoprotected in $30 \%$ sucrose solution for 4-6 days. Coronal sections from the blocks containing the locus coeruleus and the substantia nigra were cut at $30 \mu \mathrm{m}$ using a Leica freezing microtome and these were kept free-floating in $0.1 \mathrm{M}$ PBS containing $0.01 \%$ sodium azide until processed for immunohistochemistry.

Sections were either processed for avidin-biotin peroxidase complex immunohistochemistry using the appropriate rabbit or mouse ABC Vectastain kit (Vector Laboratories) in which case immunoreactivity was observed using 3,3-diaminobenzidine (DAB, Sigma) as the chromagen. For immunohistochemical studies, the polyclonal anti-TH (Pel-freeze, 
Rogers, USA; 1:500), the anti-iNOS (Calbiochem, Germany; 1:1,000), anti-3-NT (Upstate Laboratories, Lake Placid, NY, USA; 1:1,000), anti-GFAP (Promega; 1:200), and p47 phox (Santa Cruz Biotechnology, Inc., CA, USA 1:200) were raised in rabbit. Microglia were detected using monoclonal antibodies detecting anti-CD11b (clone, OX-42; 1:50) and MHCII (clone, OX-6; 1:50) (Serotec, Kidlington, Oxon, UK). For the purpose of double-labelled immunofluorescence, monoclonal antibody raised against the astrocytic marker GFAP (Chemicon) was also used in combination with polyclonal glial cell line-derived neurotrophic factor (GDNF, Santa Cruz Biotechnology, Inc., CA, USA 1:500) antibody. TH colocalisation with COX-2 (Transduction Laboratories; 1:200) was assessed using polyclonal and monoclonal antibodies, respectively. To determine the possible colocalisation of $\mathrm{p} 47_{\text {phox }}$ with microglia, dopaminergic neurons or astrocytes, double immunofluorescence was performed on nigral sections using a combination of cyclooxygenase-2 (COX-2) and $\mathrm{p} 47_{\text {phox }}$, with TH or GFAP with GDNF, respective monoclonal or polyclonal primary antibodies were used. The secondary antibodies were tagged with either fluorescein isothiocyanate (FITC) or Texas Red as fluorophores.

\section{Cell counting}

The number of tyrosine hydroxylase-immunoreactive (TH-ir) neurons at the level of the third nerve was derived from manually counting the total TH-ir neurons from 3 to 7 adjacent sections using two independent observers. Based on the counting of dopaminergic neurons throughout the $\mathrm{SN}$ at regular $100-\mu \mathrm{m}$ intervals, we previously showed that the third nerve rootlets provide a reliable anatomical landmark at which the extent of cell loss can be accurately assessed and that the extent of cell loss at this point is reflective of cell loss throughout the entire structure (Iravani et al. 2002, 2005; Bukhatwa et al. 2009). The counts obtained correlate precisely with unbiased stereology using Q4 the dissector method (see Buthatwa et al. 2009). The extent of dopamine neuronal loss was estimated by counting the number of TH-ir SN neurons at the level of the third nerve rootlets on the lesioned side compared with the control side of the SN. For counting microglial cells, using the $20 \times$ objective, a grid with a field of $500 \times 500 \mu \mathrm{m}$ (area: $0.25 \mathrm{~mm}^{2}$ ) was placed randomly at different regions within the SN. Sections were visualised using a Zeiss Axioskop II microscope equipped with an Axiocam digital camera.

\section{Data analysis}

The data for manual TH-ir cell counts in the LC and the $\mathrm{SN}$ from each treatment group were expressed as mean \pm standard error of mean (SEM). Mean of cell counts \pm SEM was compared using Student's $t$ test using
Prism 4.0 software (GraphPad, San Diego, CA USA). Where multiple groups of data were compared, as in the case of comparison of nigral cell counts following different treatments, a one-way ANOVA followed by NeumanKeul's multiple comparison post hoc test was used.

\section{Results}

DSP-4 treatment effects on TH-ir in LC

In the LC where TH-immunoreactivity (-ir) reflects noradrenergic neurons, examination of $\mathrm{ABC}$-immunoperoxidase or FITC-immunofluorescence in sections from saline-treated control rats revealed numerous large spherical TH-ir neurons (Fig. 1a, c, e, g). One week following administration of a single $50 \mathrm{mg} / \mathrm{kg}$ dose of DSP-4, there was a marked degeneration of these neurons by approximately $60 \%$ compared to saline-treated control in rats (Fig. 1b, d, f, h).

\section{Effects of DSP-4 treatment on TH-ir in SN}

In the substantia nigra (SN), where TH-ir labelling reflects dopaminergic neurons, numerous strongly stained TH-ir neurons were observed in the saline control sections while DSP-4 treated rats exhibited somewhat paler staining. However, no difference between the saline control and the DSP-4 treated rats was found in the number or morphology of TH-ir neurons. When the total number of nigral TH-ir (DAergic) neurons/hemisphere at the level of 3rd nerve was counted following nigral vehicle (PBS) administration, no significant difference could be detected between the number of TH-ir neurons in the SN of rats treated with saline (i.p.) plus nigral PBS or DSP-4 (saline: $129 \pm 17, n=4$ vs. DSP-4: $148 \pm 14 n=6 ; p>0.05$ ). The TH-ir neuronal counts in this group were not significantly different from the neuronal counts of the contralateral SN of either the LPS plus saline or LPS plus DSP-4 treated animals (Fig. 2).

Following supra-nigral LPS $(4 \mu \mathrm{g})$ administration in saline (i.p.) pre-treated rats, an approximately $50 \%$ loss of ipsilateral TH-ir neurons occurred compared to the contralateral SN (Fig. 2). In rats pre-treated with DSP-4 $(50 \mathrm{mg} / \mathrm{kg})$, loss of TH-ir neurons following supra-nigral LPS was not significantly different (Fig. 2c, d, e).

LPS induced microgliosis in control or DSP-4 treated rat $\mathrm{SN}$

In the contralateral SN of DSP-4 plus LPS, or in rats pre-treated with DSP-4 alone, a modest 3-NT expression was frequently observed within small cellular entities resembling microglia (Fig. 3A). In rats pre-treated systemically with saline, $4 \mu \mathrm{g}$ LPS led to marked expression of 3-NT-ir (Fig. 3Bb, d) and
252

253 


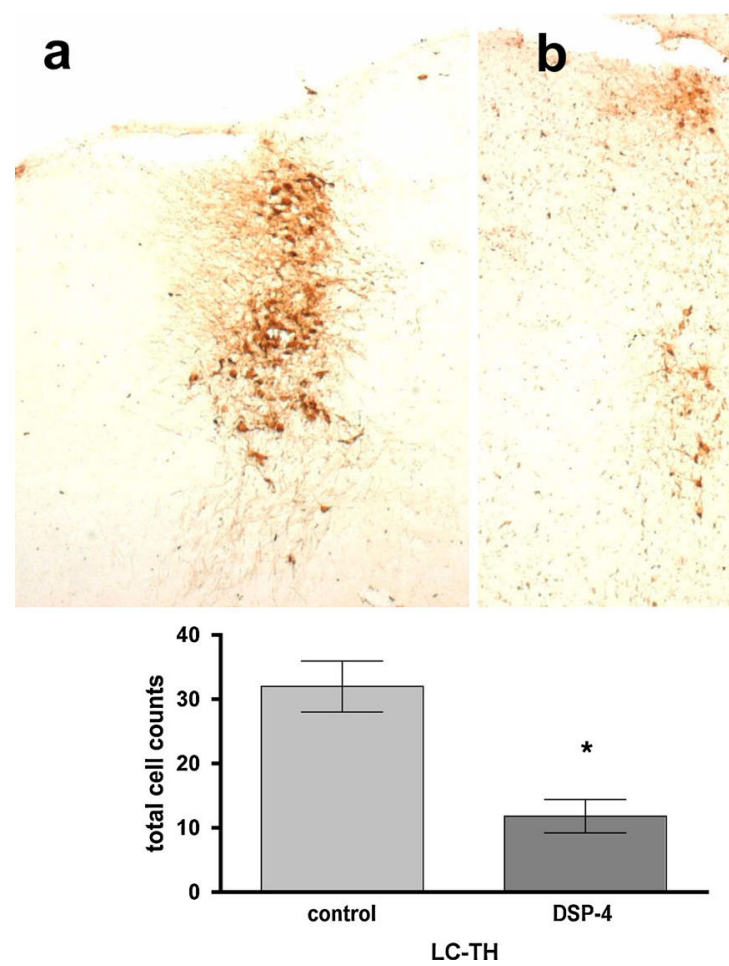

Fig. 1 Marked reduction of TH-ir neurons was observed in the locus coeruleus following administration of $50 \mathrm{mg} / \mathrm{kg}$ (i.p.) DSP-4. In saline-treated control rats, locus coeruleus contained numerous TH-ir neurons (a peroxidase -ir, c, e, $\mathbf{g}$ fluorescence-ir), but 1 weeks

259 iNOS-ir (Fig. 3Cb, e), while the contralateral SN in saline pre26(AQ6 treated rats was devoid of 3-NT-ir (Fig. 3Ba) or iNOS-ir 261 (Fig. 3Ca, d). In rats pre-treated with DSP-4, LPS adminis262 tration resulted in markedly reduced expression of both 3-NT 263 (Fig. 3Bc, e) and iNOS-ir (Fig. 3Cc, f).
In the untreated $\mathrm{SN}$, the $\mathrm{OX}-42$ positive microglia remained "ramified" and uniformly distributed throughout this structure in an "un-activated" state. Rarely, a few OX42-ir was observed following supranigral administration of saline (Fig. 4Aa). Following DSP-4 alone, there was evidence of partial activation of microglia (Fig. $4 \mathrm{Ab}$, see fine arrows). Following LPS administration in saline-pretreated rats, OX-42-ir cells became fully activated as evidenced by the thickening of processes and acquisition of amoeboid morphology (Fig. 4Ac). When the LPS-treated SN was assessed for OX-6-ir, a marked increase in the number of OX-6-ir expressing stellate morphology (Fig. 4Ba, b) was observed. In rats pre-treated with DSP-4, the number of OX-6+ve activated microglia was markedly reduced (Fig. 4C). Furthermore, following DSP-4 treatment, the morphology of the OX-6-ir cells was also altered. These cells lost their stellate characteristic and became more punctate (Fig. 4Bc, d). Overall, there was a significantly smaller number of OX-6-ir cells following DSP-4 pretreatment (Fig. 4C).
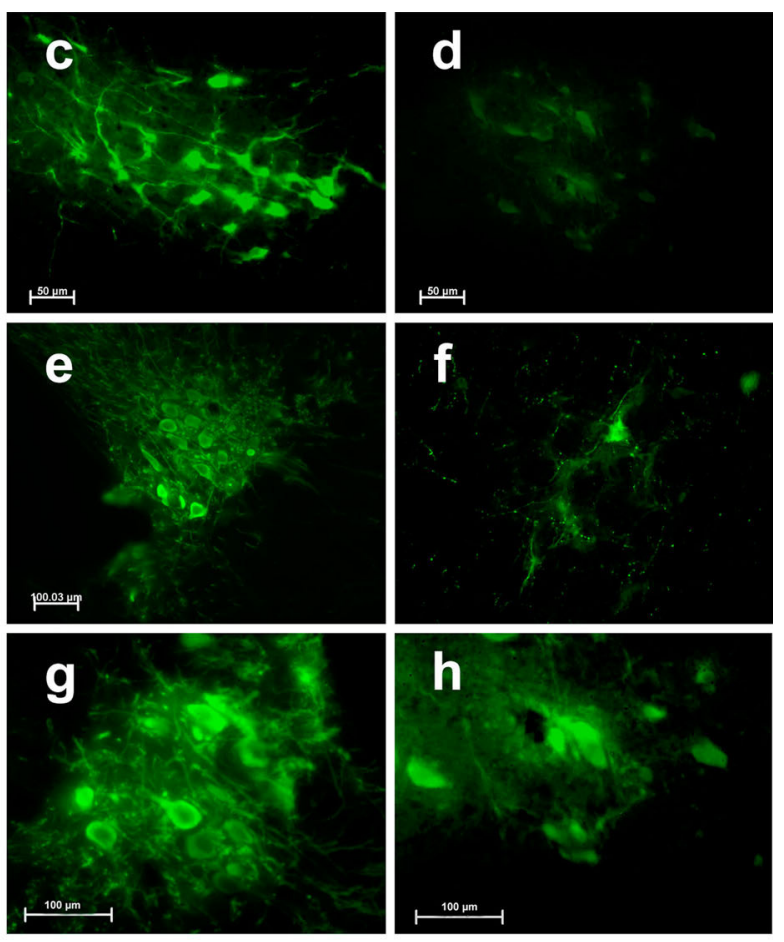

following a single i.p. administration of DSP-4, the number of TH-ir neurons was markedly reduced at all rostral $(\mathbf{c}, \mathbf{d})$, middle $(\mathbf{e}, \mathbf{f})$ and caudal levels $(\mathbf{g}, \mathbf{h})$. The histogram represents mean \pm SEM total cell counts from 5 to 7 rats per group. $* p<0.05$, Student's unpaired $t$ test

LPS induced glial and neuronal $\mathrm{p} 47_{\text {phox }}$ expression in saline or DSP-4 pre-treated rats

Following supranigral LPS administration in saline pretreated (i.p.) rats, marked expression of nigral p47 phox-ir was observed (Fig. 5Aa, Ba). Double-labelled immunofluorescence of p47 phox with either OX-42 (Fig. 5Ab) or OX-6 (Fig. 5Bb) showed a good staining overlap (Fig. 5Ac, Bc, see fine arrows). In rats pre-treated with DSP-4, there was a poor overlap of OX-42 (Fig. 5Af) and OX-6 (Fig. 5Bf) with p47 phox-ir Only rarely did merging OX-42-ir or OX-6-ir with p47 phox-ir images show an overlap.

We assessed the morphology and population of $447_{p h o x-\text { ir }}$ following LPS in the SN of either the saline or the DSP-4 pre-treated rats. The expression of p47 phox-ir in the $\mathrm{SN}$ of saline pre-treated rats was confined to numerous small $(<10 \mu \mathrm{m}$ diameter) cells (Fig. 6a, c), distributed throughout the treated $\mathrm{SN}$ compacta $(\mathrm{SNc})$ and the $\mathrm{SN}$ reticulata (Fig. 6a). In the DSP-4 pre-treated rats, most of p47phox-ir was confined to larger $(>15 \mu \mathrm{m})$ cells located in the region corresponding to the SNc (Fig. 6b, e). These p47 $7_{\text {phox-ir }}$ cells had neuron-like morphology (Fig. 6e). There were also numerous small cells in the $\mathrm{SNr}$ that were $\mathrm{p} 47_{\text {phox-ir }}$ (Fig. 6d) but their population was less dense than those observed in rats treated with LPS alone (Fig. 6f, g).

\begin{tabular}{|c|c|c|c|c|}
\hline & Journal : Large 702 & Dispatch & 25-4-2014 & Pages: $\mathbf{1 3}$ \\
\hline & $\begin{array}{l}\text { Article No. : } \mathbf{1 2 2 3} \\
\text { MS Code : } \\
\text { JNT-D-13-00293 }\end{array}$ & $\begin{array}{l}\square_{\mathrm{CP}}^{\mathrm{LE}} \\
\mho_{\mathrm{C}}\end{array}$ & & $\begin{array}{l}\square \text { TYPESET } \\
\boldsymbol{D I S K}_{\text {DISK }}\end{array}$ \\
\hline
\end{tabular}


Fig. 2 Loss of TH-ir in the SN following nigral administration of LPS. In the saline (i.p.) pretreated rats, administration of $4 \mu \mathrm{g}$ LPS led to a marked reduction of TH-ir neurons in the SN. Compared to control (a) and DSP-4 pre-treated rats (b), supranigral administration of LPS alone (c) or following systemic DSP-4 (d) marked loss of TH-ir occurred. The lower panel (e) summarises the TH-ir cells counts following different treatments. TH-ir cell counts in the SN of DSP-4 pre-treated rats and the contralateral $\mathrm{SN}$ of other group did not differ significantly, but LPS administration significantly reduced $\mathrm{TH}$-ir cells in both saline and DSP-4 pre-treated groups. $* p<0.05$, one-way ANOVA followed by NeumanKeul's multiple comparison test
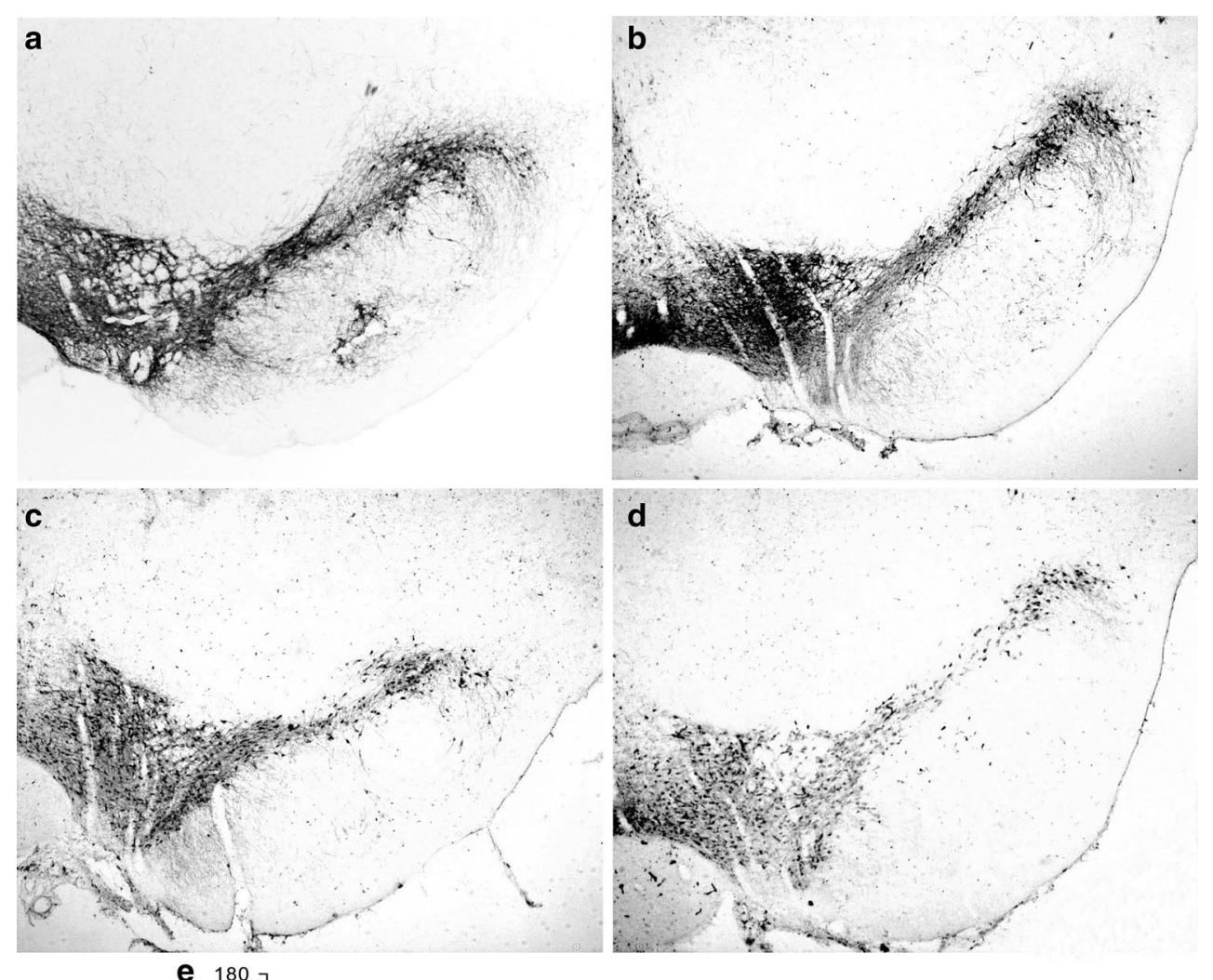

d

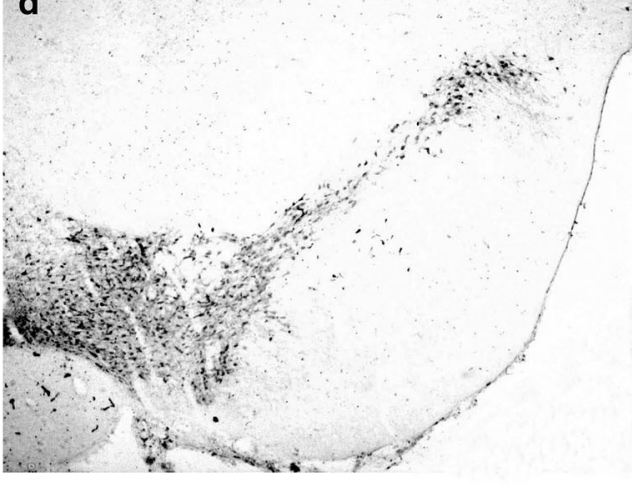

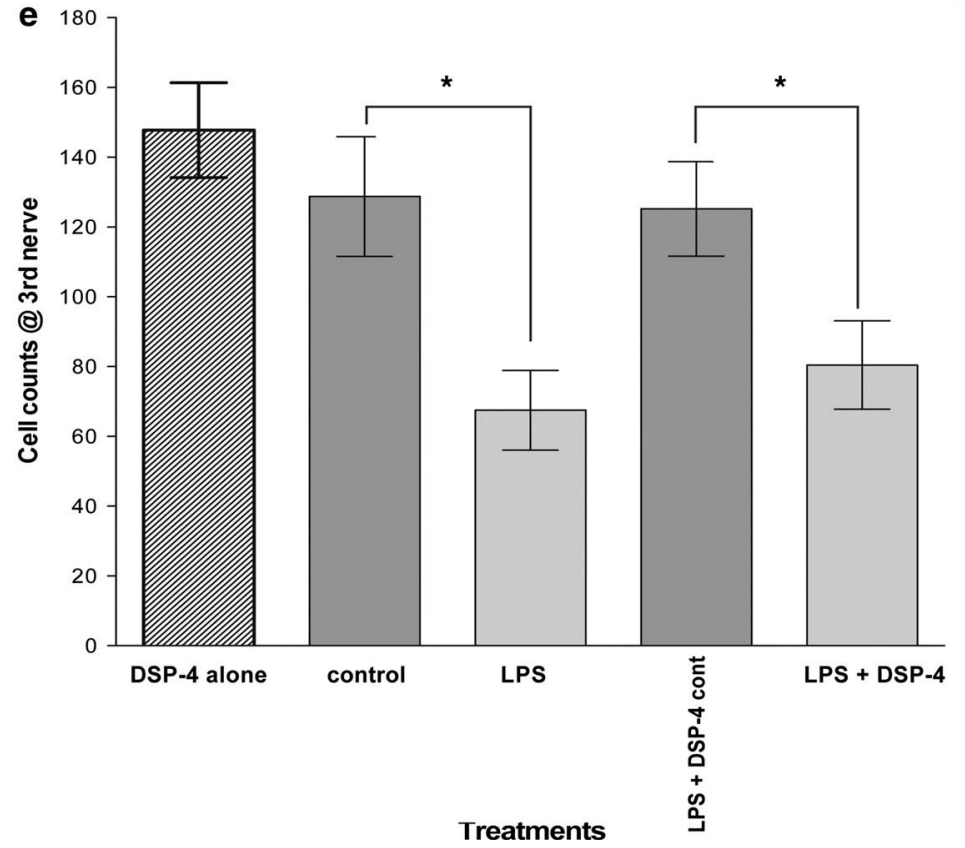

Co-localisation of TH with $\mathrm{p} 47_{p h o x}$ and COX-2

Double immunofluorescence using $\mathrm{TH}$ and $\mathrm{p} 47_{\text {phox }}$ following LPS in saline pre-treated rats showed no colocalisation of TH-ir in small $\mathrm{p} 47_{p h o x-\text { ir }}$ cells. Only rarely was the colocalisation of TH-ir and p47 $7_{p h o x-\text { ir }}$ observed in large cells with neuronal morphology following LPS alone (Fig. 7Aa-c, see large arrow). However, in rats pre-treated with DSP-4, administration of LPS resulted in nearly all TH-ir neurons expressing p47 phox-ir (Fig. 7Ad-f).

Supra-nigral LPS administration led to marked expression of COX-2 within the TH-ir neurons but no COX-2-ir in the contralateral SN (Fig. 7Ba-c). However, following LPS administration in the DSP-4 treated rats, virtually no $\mathrm{TH}$ and $\mathrm{COX}-2$ co-localisation was seen (Fig. 7Bd-f).

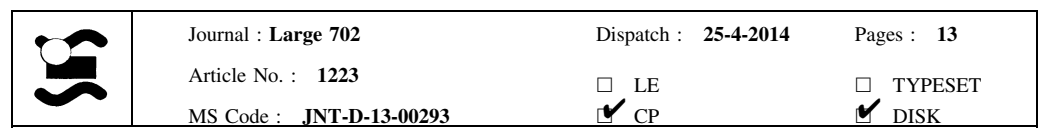




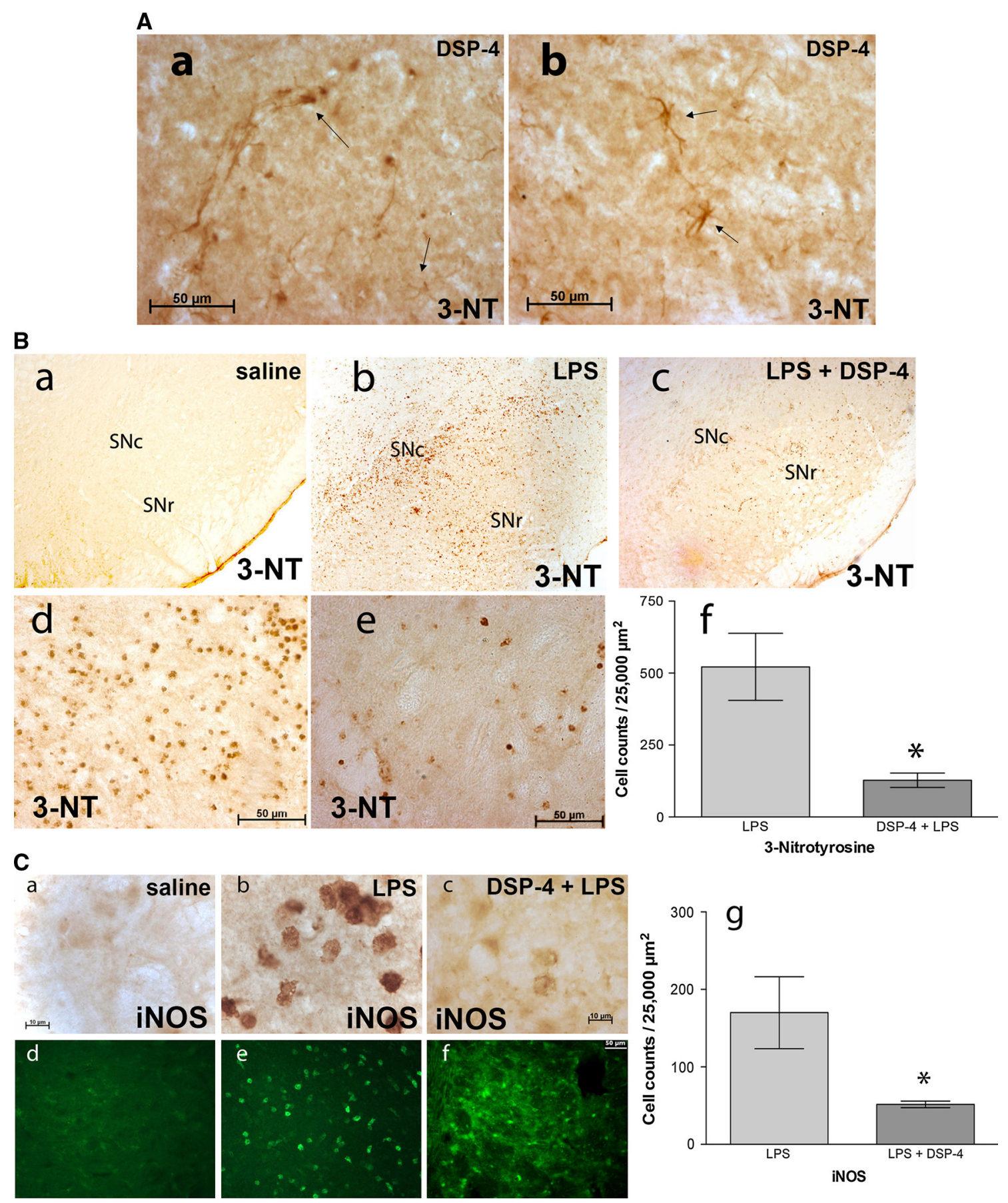

Fig. 3 The effects of DSP-4 alone A and LPS on 3-nitrotyrosine (3-NT; B) and inducible nitric oxide synthase (iNOS; C) expression in saline ( $\mathbf{B} a, \mathbf{C} a)$ pre-treated rat SN. In DSP-4 pretreated rats cells with glial cell morphology ( $a$ and $b$, see arrows) were frequently observed in the $\mathrm{SN}(\mathbf{B} a, b)$. Following supranigral LPS in the saline group, numerous punctate cellular structures expressing 3-NT-ir (mag: $\times 4$; $\mathbf{A} b$; mag: $\times 40 ; \mathbf{A} d$ ) and a marked iNOS expression in amoeboid cells $(\mathbf{B} b, e$; mag: $\times 100$ and $\times 20$, respectively) were observed.
Administration of LPS following DSP-4 markedly reduced 3-NT (B $c$, $\times 4 ; \mathbf{B} e, \times 40 ;$ scale bars $50 \mu \mathrm{m})$ and the iNOS-ir cells $(\mathbf{C} c, f)$. Examination at high optical magnification (mag: $\times 100 ; \mathbf{C} b, c)$ revealed that these cells had a different morphology. Data for 3-NT and iNOS-ir punctate cell counts in an area of 25,000 $\mu \mathrm{m}^{2}$ from LPS alone or LPS + DSP-4 treated rats are expressed as mean \pm SEM and shown in the lower panels. $* p<0.05$, unpaired Student's $t$ test

\begin{tabular}{|l|lll|}
\hline Journal : Large 702 & Dispatch : 25-4-2014 & Pages : $\mathbf{1 3}$ \\
Article No. : $\mathbf{1 2 2 3}$ & $\square$ LE & $\square$ TYPESET \\
& MS Code : JNT-D-13-00293 & $\sim_{\text {CP }}$ & $\checkmark$ DISK \\
\hline
\end{tabular}


A

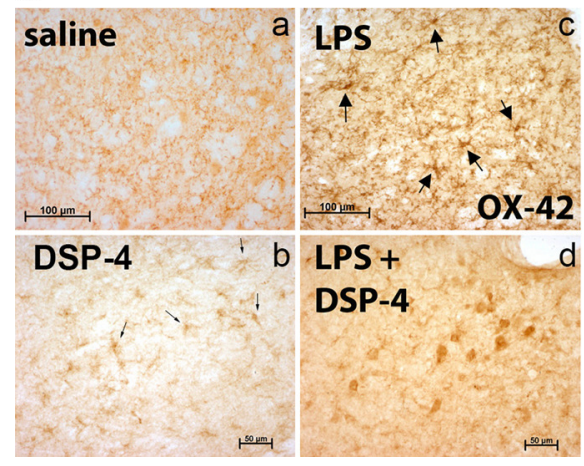

B

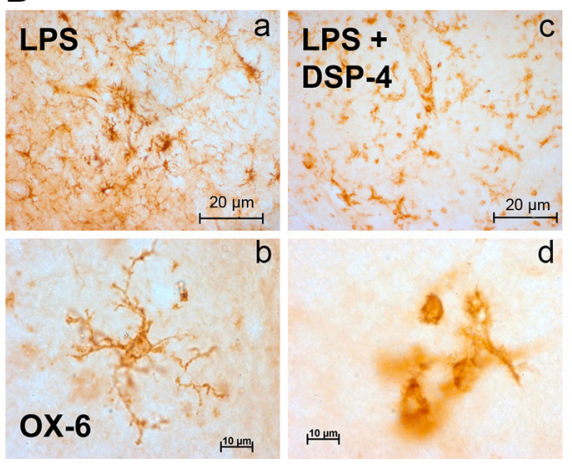

C

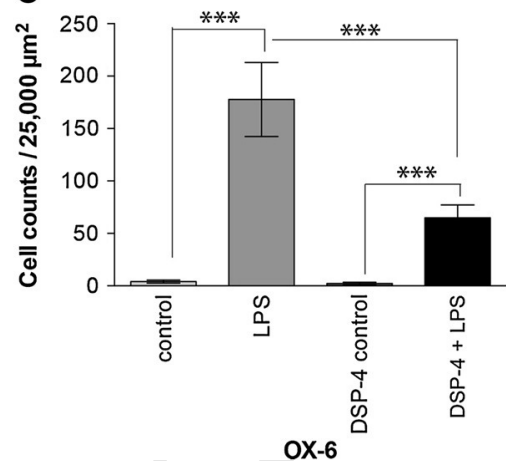

Fig. 4 The effect of LPS, DSP-4 and DSP-4 plus LPS on microglial expression in SN. OX-42-ir in saline-treated rats showed the presence of numerous "resting" microglia (A $a$ ), but in DSP-4 treated rats, several partially activated OX-42 positive microglia were evident (small arrows; $\mathbf{A} b$ ). Following supranigral LPS administration, microglia entered an activated state, and several amoeboid cellular structures were visible (Ac; large arrows). Administration of LPS following DSP-4 pre-treatment resulted in fewer amoeboid OX-42-ir cells $(\mathbf{A} d)$. Following LPS alone, numerous OX-6 positive cells were observed in the SN $(\mathbf{B} a)$. These cells had prominent stellate characteristics $(\mathbf{B} b)$. LPS administration following DSP-4 led to appearance of punctate OX-6 positive cells $(\mathbf{B} d)$. Since unlike OX-42 there was little or no OX-6 immunoreactivity under resting condition, for ease and accuracy of the cell counts only the number of OX-6+ve cells was recorded. Panel $(\mathbf{C})$ shows the mean \pm SEM number of OX-6 cells exhibiting stellate morphology $(n=8)$. LPS led to a marked and a highly significant increase in the number of stellate OX6 positive cells in vehicle or DSP- 4 treated rats $(p<0.001$; one-way ANOVA), but compared to LPS alone there was a marked and significant reduction $(p<0.001$; one-way ANOVA; followed by Neuman-Keul's multiple comparison test) in the increase of stellate OX-6 cell counts in rats that were pre-treated with DSP-4
Fig. 5 Microglial (OX-42, A and OX-6, B positive cells) co-localisation with $\mathrm{p} 47 \mathrm{phox}$ following supranigral LPS in saline pre-treated (A $a-c$;

$\mathbf{B} a-c)$ or LPS following DSP-4 pre-treatment (Ad-f; $\mathbf{B} d-f)$. In saline pre-treated rats, LPS led to co-localisation of OX-42 (Ac small arrows) or OX-6-ir (Bc, small arrow) with p47phox-ir. Following LPS administration in DSP-4 pre-treatment rats, there was no colocalisation of p47phox with OX-42 (Af) and OX-6 (Bf)
A
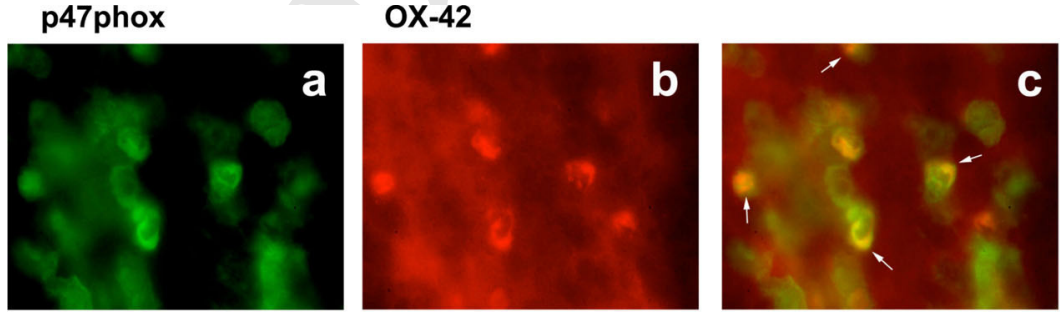

LPS

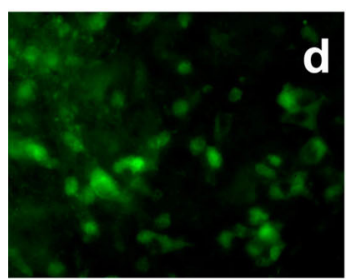

DSP-4 LPS
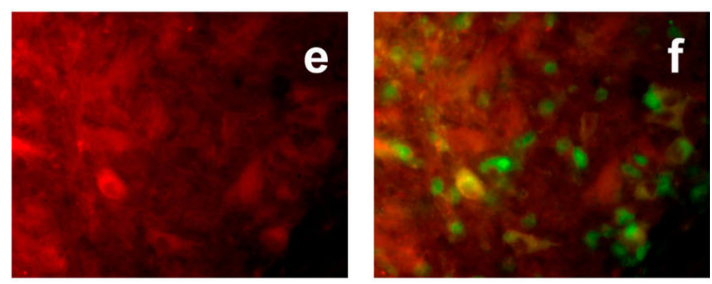

B

\section{p47phox}

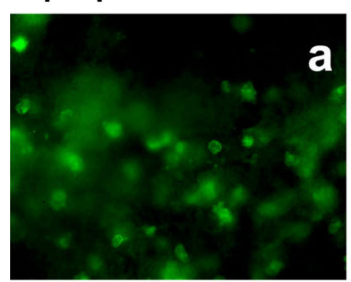

Vehicle LPS

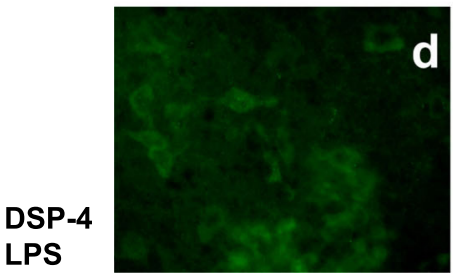

\section{OX-6}
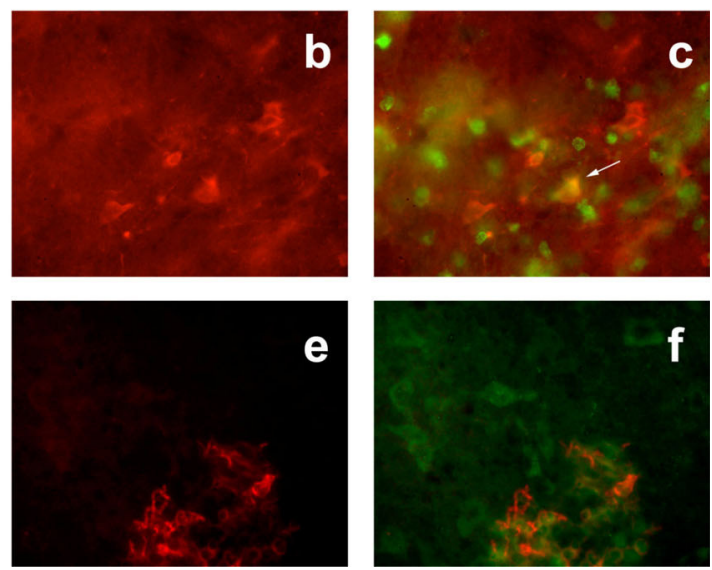

\begin{tabular}{|l|lll|}
\hline Journal : Large 702 & Dispatch : 25-4-2014 & Pages : 13 \\
Article No. : $\mathbf{1 2 2 3}$ & $\square$ LE & $\square$ TYPESET \\
MS Code : JNT-D-13-00293 & $\sim_{\text {CP }}$ & $\checkmark$ DISK \\
\hline
\end{tabular}


Fig. 6 In saline pre-treated rats, LPS administration led to a prominent $\mathrm{SNc} / \mathrm{SNr}$ expression of p47phox-ir in cells with predominantly punctate microglial morphology (a, c, broad arrows). In the $\mathrm{SN}$ of rats treated with LPS following DSP-4 pre-treatment, fewer punctate cells were $\mathrm{p} 47$ phox-ir (b, d) in the $\mathrm{SNr}$ but there was extensive neuronal expression of p47phox in the $\mathrm{SNc}$ region (b, e, cell within the fine arrows). Panels $\mathbf{f}$ and $\mathbf{g}$ show mean \pm SEM nigral p47phox-ir cell counts. There were a significantly greater number of cells with glial morphology that were counted following LPS alone (f). Expression of p47phox-ir cells with neuronal morphology was significantly greater following DSP-4 alone or DSP-4 plus LPS (g). $* p<0.05$; ** $p<0.001$, Oneway ANOVA, followed by Neuman-Keul's multiple comparison test
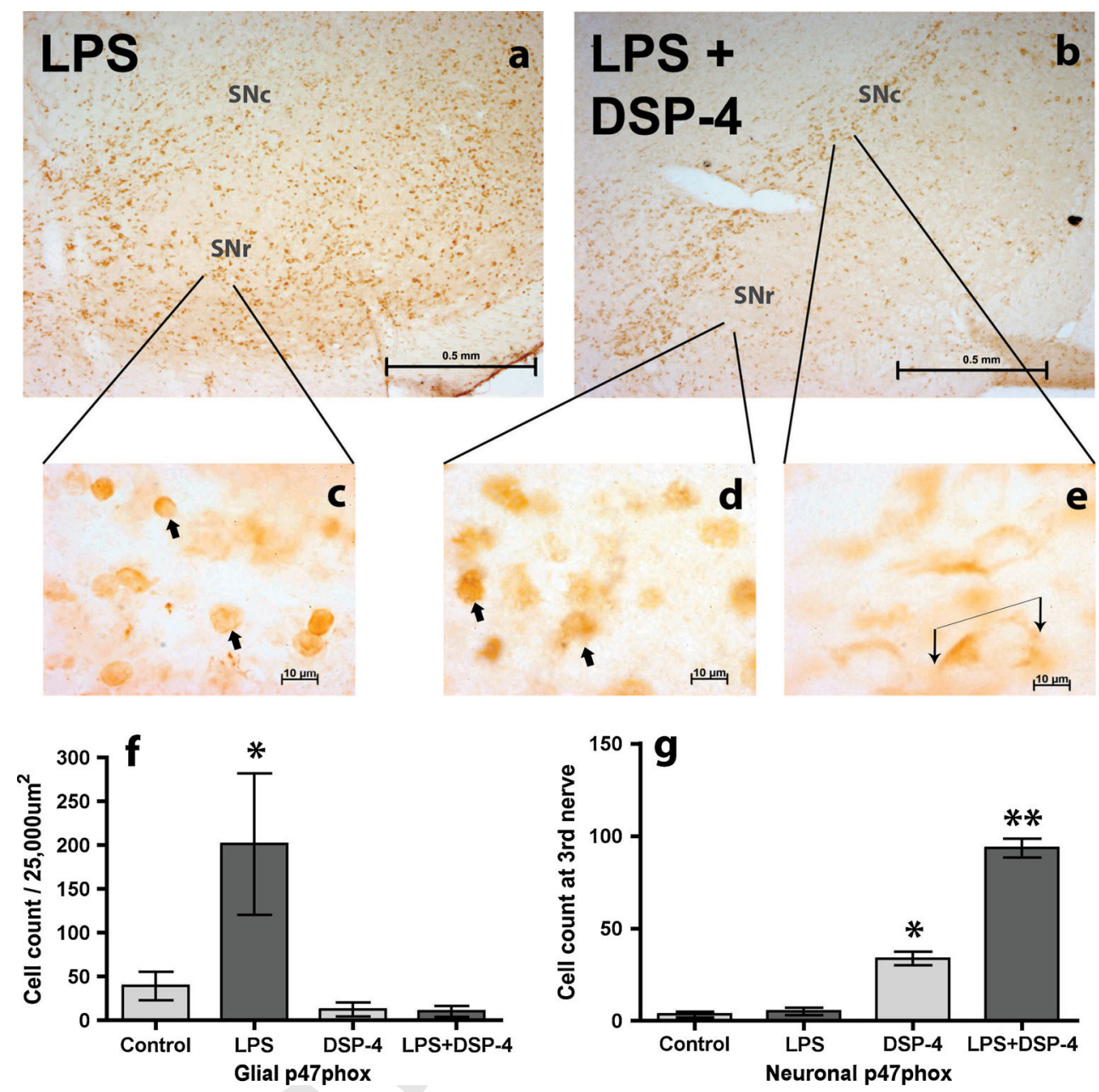

\section{Effect of DSP-4 treatment on astrocytosis}

In the $\mathrm{SN}$ of the control, saline (i.p.) pre-treated rats, only a few GFAP-ir astrocytes were seen. These GFAP-ir cells had a relatively faint staining, with a fine fibrillar structures and a very small central core. Administration of LPS significantly up-regulated GFAP-ir in the ipsilateral SN, compared to the contralateral SN or the $\mathrm{SN}$ of saline pretreated control animals. Following LPS alone, the number of GFAP-ir astrocytes increased by more than $100 \%$ $(138 \pm 18$ vs. $267 \pm 27 ; p<0.05$; Fig. 8$)$. Eight days following DSP-4 (i.p.) alone, a marked proliferation of GFAP-ir cells took place in the $\mathrm{SN}$ in both hemispheres equally, such that the number of these cells was even greater than those seen following LPS in the saline pretreated rats. Furthermore, in addition to a significant increase in number, the GFAP-ir cells had broader fibrillar morphology, though appeared to be shorter in length, but their central cores were greatly enlarged-nuclear hypertrophy. In rats pre-treated with DSP-4, supranigral administration of LPS did not lead to a further increase in the number or further hypertrophy of the GFAP-ir. There was an increase in number of GFAP-ir in the ipsilateral SN compared to the contralateral SN (ipsilateral SN: $338 \pm 23$; contralateral SN: $314 \pm 17$ ), but the difference was not statistically significant (see Fig. 8).

Localisation of glial cell line-derived neurotrophic factor (GDNF) in astrocytes and the effect of DSP-4 pre-treatment

Following LPS administration in saline (i.p.) pre-treated rats, up-regulation of numerous GDNF-ir was observed within GFAP + ve astrocytes (Fig. 9a-f). In the control SN administered with PBS, GFAP-ir was only faintly expressed and only few GFAP + ve astrocytes were also GDNF positive. In rats pre-treated with systemic DSP-4 8 days earlier, LPS administration led to a general absence of colocalisation of GDNF within GFAP-ir astrocytes, although GFAP-ir was robustly up-regulated (Fig. 9g-i). In DSP-4 treated rats, astrocytes displayed marked hypertrophy exhibiting more rounded central morphology with fewer ramifications, though fibrillar diameters appeared to be broader.

\begin{tabular}{|l|lll|}
\hline & Journal : Large 702 & Dispatch : 25-4-2014 & Pages : $\mathbf{1 3}$ \\
Article No. : $\mathbf{1 2 2 3}$ & $\square_{\mathrm{CP}}^{\mathrm{LE}}$ & $\checkmark_{\mathrm{TISK}}^{\mathrm{TYPESET}}$ \\
\hline
\end{tabular}


Fig. 7 A Co-localisation of TH-ir with p47phox within SN $(\mathbf{A} a-c)$. Following saline (i.p) pre-treatment, LPS administration led to few surviving TH-ir neurons expressing p47phox-ir (top panel, large arrows) but numerous small cells with microglial morphology expressed $\mathrm{p} 47 \mathrm{phox}$-ir (A $b$, small arrows). However, in DSP-4 pre-treated rats, LPS administration led to nearly all surviving $\mathrm{TH}$-ir neurons $(\mathbf{A} d)$ to express p47phox-ir $(\mathbf{A} e, f)$.

B Following saline pretreatment, TH-(B $a)$ and COX-2ir $(\mathbf{B} b)$ were colocalised in surviving dopaminergic neurons following LPS administration $(\mathbf{B} a-c)$. Following DSP-4 pretreatment, administration of LPS led to COX-2-ir to be poorly co-localised with TH-ir. Arrow-heads TH-ir neurons, small arrows COX-2-ir neurons

\section{Discussion}

A TH

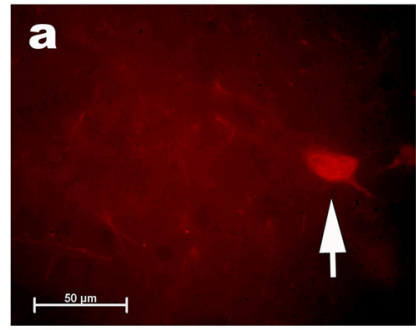

\section{p47phox}

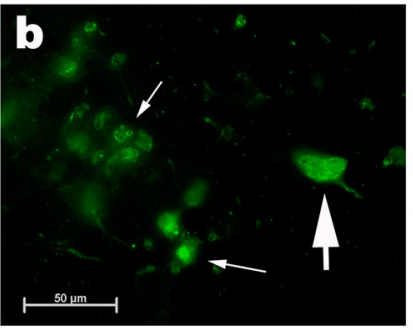

\section{LPS}
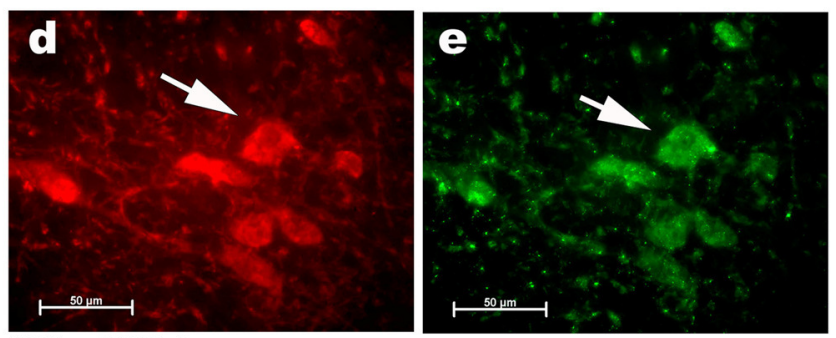

LPS + DSP-4

B $\mathrm{TH}$

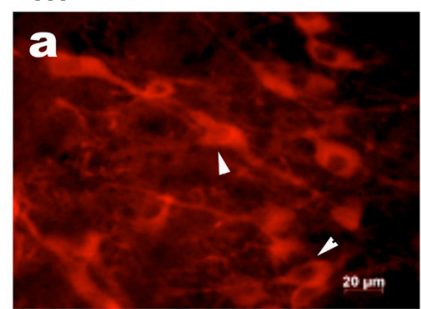

cox-2
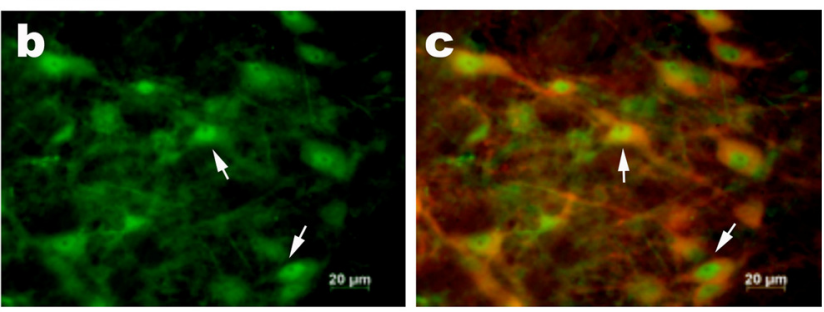

LPS
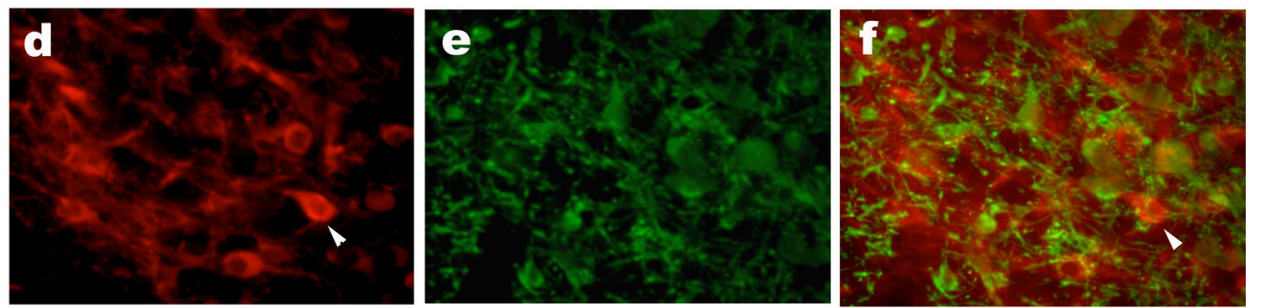
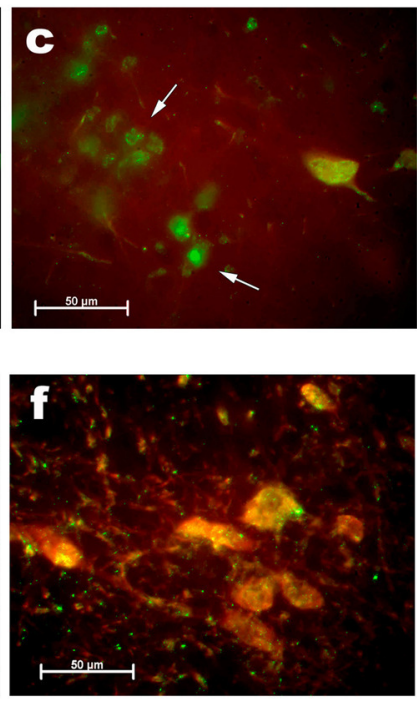

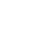

LPS + DSP-4 

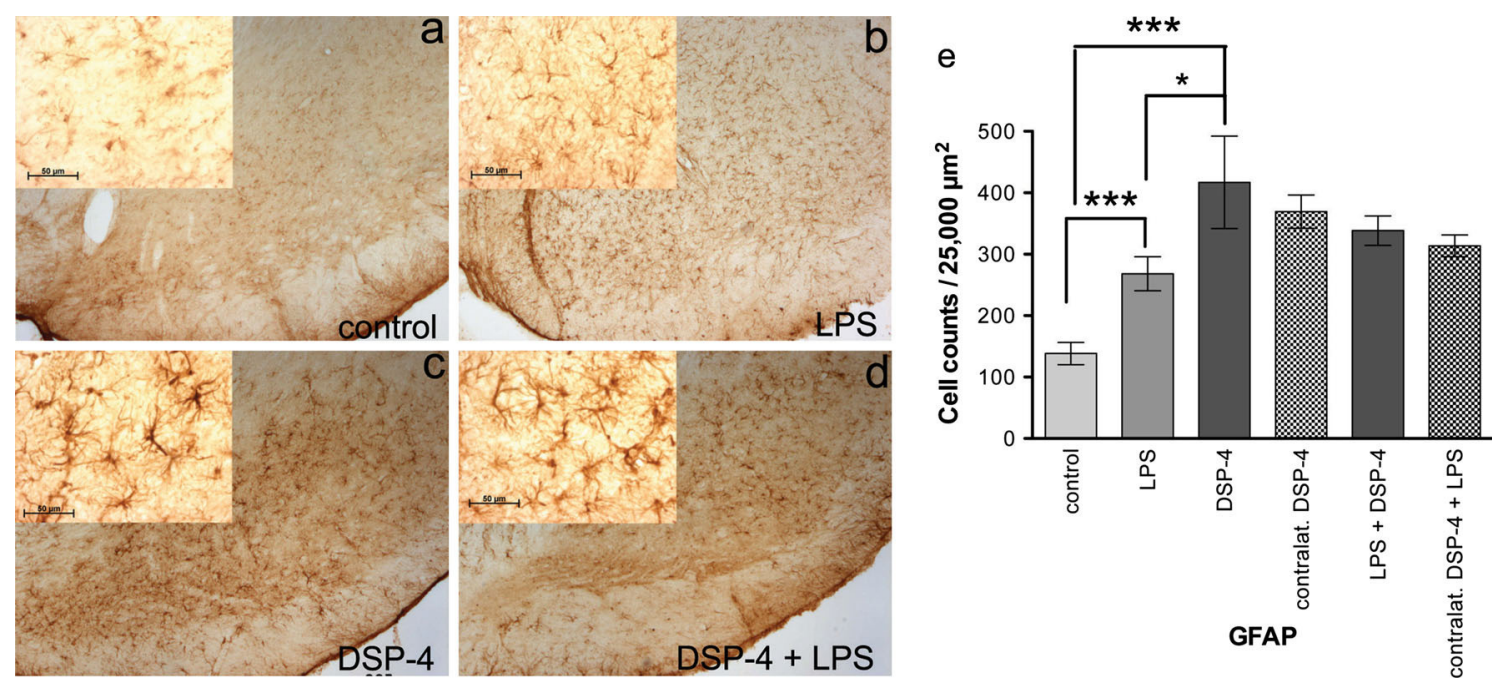

Fig. 8 GFAP immunoreactivity in saline (a) DSP-4 alone (b) LPS (c) and LPS in DSP-4 pre-treated nigra (d). Compared to the control SN administered with PBS (a) where little GFAP-ir astrocytosis was observed, LPS administration resulted in marked activation of GFAPir (b). In rats pre-treated with DSP-4 alone (c), a much greater level of GFAP-ir was observed bilaterally compared to saline pre-treated rats and supranigral LPS where the increase in GFAP-ir was observed only in the ipsilateral SN. In rats pre-treated with DSP-4 and supranigral LPS administration, expression of GFAP-ir was not further enhanced (d). Panel e compares the number of GFAP-ir cells in a grid area of $25,000 \mu \mathrm{m}^{2}$ in the ipsilateral and the contralateral $\mathrm{SN}$. GFAP-ir cells were counted and expressed as mean $\pm \mathrm{SEM}$ $(n=8)$. Note that in all conditions, DSP-4 was administered as pretreatment; the number of GFAP-ir in the contralateral SN was similarly increased compared to the ipsilateral $\mathrm{SN} . * p<0.05$; $* * * p<0.0001$; one-way ANOVA, followed by Neuman-Keul's multiple comparison test
Fig. 9 Nigral colocalisation of GFAP and GDNF following LPS in saline pre-treated (a-f) and DSP-4 pre-treated (g-i) rats. Supranigral administration of $4 \mu \mathrm{g}$ LPS results in marked astrocytosis (a, d) and expression of GDNF (b) in saline pre-treated rats. At high magnification $(\times 100)$, a prominent expression of GDNF within GFAP + ve astrocytes is observed (f). In rats pre-treated with DSP-4, supranigral administration of LPS resulted in marked astrocytosis (g), but little GDNF expression within GFAP + ve astrocytes was evident $(\mathbf{h}, \mathbf{i})$

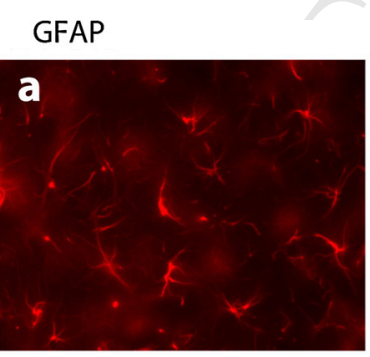

GDNF
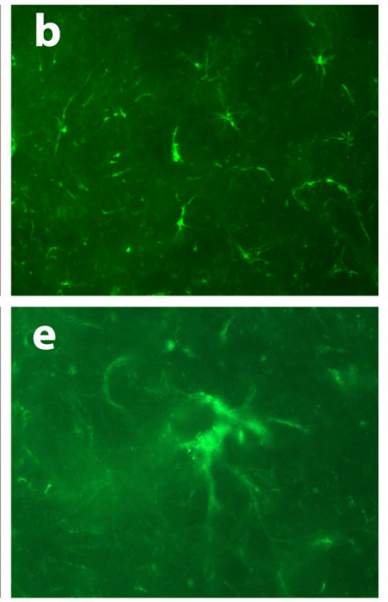

$4 \mu \mathrm{LPS}$
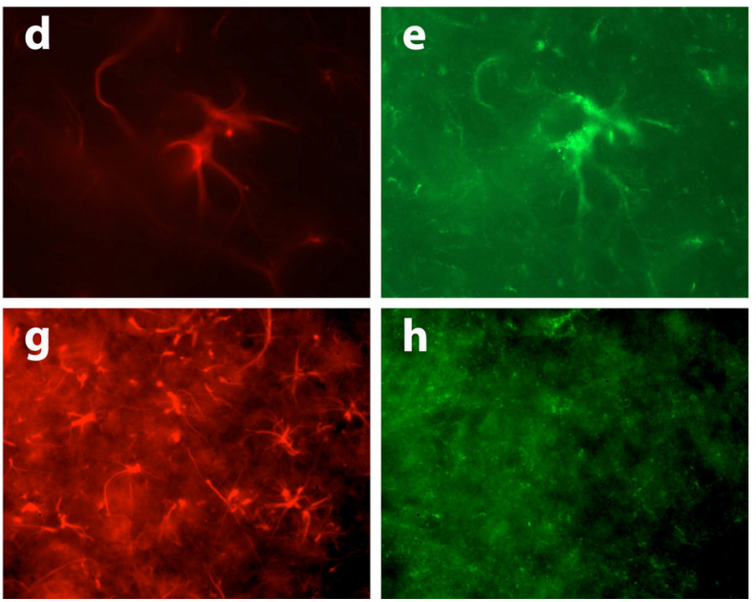

merge
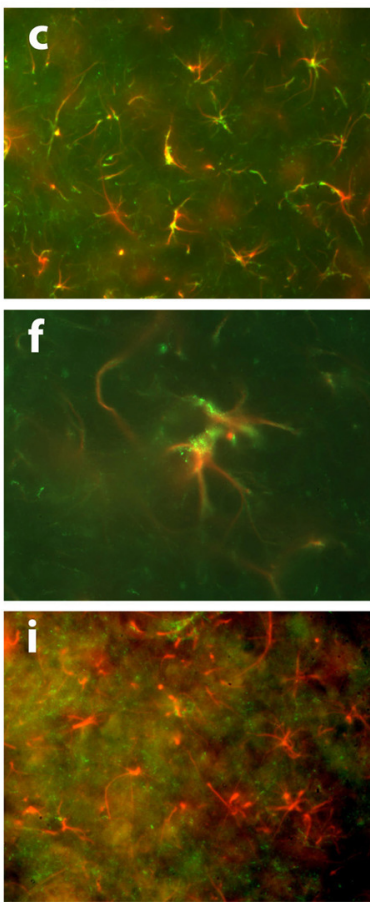

in the inflammatory response to LPS in SN were seen as predicted by our original hypothesis.

LPS administration into SN induced both astrocytosis and microgliosis in confirmation of our previous studies
(Iravani et al. 2002, 2005, 2008). The LPS-induced astrocytosis was accompanied by an up-regulation of GDNF as shown by co-localisation with GFAP immunoreactivity (Iravani et al. 2012). However, surprisingly DSP-4

\begin{tabular}{|c|c|c|c|c|}
\hline & Journal : Large 702 & Dispatch & 25-4-2014 & Pages : \\
\hline & $\begin{array}{l}\text { Article No. : } \mathbf{1 2 2 3} \\
\text { MS Code : JNT-D-13-00293 }\end{array}$ & $\begin{array}{l}\square \\
\boldsymbol{V}_{\mathrm{CP}}^{\mathrm{LE}} \\
\end{array}$ & & $\begin{array}{ll}\square & \text { TYPESET } \\
\boldsymbol{V} & \text { DISK } \\
\end{array}$ \\
\hline
\end{tabular}


treatment alone also led to a marked astrocytosis in the SN which was greater than that observed for LPS alone, even though no SN neuronal loss occurred, but there was no upregulation of GDNF. Following DSP-4 treatment alone or DSP-4 combined with LPS treatment, there was little evidence of GFAP and GDNF co-localisation despite the extensive astrocyte proliferation. These observations suggest that the NAergic input from LC is essential for the normal functioning of astrocytes and trophic factor production and that the phenotype of reactive astrocytosis depends strongly on the nature injury-inducing stimulus (see Zamanian et al. 2012).

Loss of LC noradrenergic input to substantia nigra also had a marked effect on the response of microglia to LPS administration. In the normal SN, microglia with ramified morphology are abundantly expressed as identified by OX42 immunoreactivity with a few MHC-II macrophagic cells with stellate or rounded morphology that are OX-6 immunoreactive. This is consistent with the presence of abundant resting microglia. Following LPS treatment, OX42 positive cells in $\mathrm{SN}$ lost their ramifications, became enlarged and had amoeboid morphology, and numerous OX-6 positive cells with predominantly stellate morphology were present. DSP-4 treatment alone induced a shortening and broadening of OX-42 positive cell branching indicative of partial microglial activation. This suggested that depletion of NA could initiate modest microglial activation in addition to the effects seen on astrocytic function. However, following DSP-4 pre-treatment, LPS administration resulted in a smaller increase in both OX-42 and OX-6 immunoreactivity compared to that seen with LPS alone suggesting a controlling influence of LC input on the inflammatory response to LPS.

To determine the functional importance of the inflammatory response induced by loss of LC input, we assessed markers of both oxidative and nitrative stress associated with gliosis. NO derived from iNOS is an important contributor to LPS-induced nigral dopaminergic cell loss as it becomes highly toxic when combined with superoxide to form peroxynitrite that then reacts with tyrosine residues to form 3-NT (Iravani et al. 2006). We, therefore, looked at the effect of NA depletion on both iNOS expression and 3-NT formation. LPS alone induced a marked increase in iNOS expression that co-localised with OX-42- and OX-6 immunoreactive cells and induced immunoreactivity for 3-NT (Iravani et al. 2005). Following combined DSP-4 and LPS treatment, the number of iNOS expressing cells and the intensity of 3-NT immunoreactivity were reduced in line with the observation of reduced microglial number. To assess alterations in oxygen radical formation, $\mathrm{p} 47_{p h o x}$ was used as a marker of up-regulated NADPH-oxidase activity (Lavigne et al. 2001; Iravani et al. 2005). Following nigral LPS administration, p47 phox was up-regulated and co- localised with both OX-42 and OX-6 immunoreactive cells. This implies that activated microglia produce both NO and $\mathrm{O}_{2}{ }^{-}$to form peroxynitrite. However, following combined DSP-4 and LPS treatment, the number of glial cells in SN expressing $\mathrm{p} 47_{\text {phox }}$ was markedly reduced. In contrast, the majority of $\mathrm{p} 47_{\text {phox }}$ immunoreactivity was now present in TH-positive neurons. This suggests that in the absence of NA, dopaminergic neurons become directly involved in the generation of oxidative stress. Finally, we assessed superoxide formation in dopaminergic neurons using $\mathrm{COX}-2$ immunoreactivity. In the normal $\mathrm{SN}, \mathrm{COX}-2$ immunoreactivity is not present in either neurons or in glia. However, as previously reported, following LPS treatment, there was prominent expression of COX-2 in $\mathrm{TH}$ immunoreactive neurons (O'Banion 1999; Teismann et al. 2003; de Meira Santos Lima et al. 2006). However, following combined DSP-4 and LPS treatment, COX-2 immunoreactivity was not co-localised with TH-positive cells. Recently, Schlachetzki et al. (2010) have shown that combination of noradrenaline and LPS in cortical primary microglial culture enhanced COX-2 expression. In the present study, LPS following NA depletion by DSP-4 resulted in downregulation of COX-2 suggesting an important role for NA in the regulation of inflammatory processing and the role of COX2 , which is implicated therein. Consequently, it is possible that loss of LC input to $\mathrm{SN}$ removes the NA-mediated neuronal COX-2 response to inflammatory event. It also suggests that loss of LC input to SN removes the response of neuronal COX-2 to inflammatory events.

In conclusion, LPS-induced nigral dopaminergic cell loss is not exacerbated by the loss of LC noradrenergic input in the same way that occurs with directly acting neuronal toxins such as MPTP and 6-OHDA. Rather, there is a complex effect on glial cell activation and markers of inflammatory change. A reduction in glial markers of nitrative and oxidative stress following loss of LC input suggests that LPS-induced nigral cell death should be reduced but this might be balanced by the decrease in trophic factor production that also ensues. The complex sequence of events that occurs in the regulation of inflammatory events in SN following loss of LC input may have relevance to early neuronal loss in PD. A change in the ability of glial cells to 'protect' nigral dopaminergic neurons from toxic events may affect their survival and the extent of LC loss may then partially determine the rate of disease progression.

\section{References}

Archer T, Jonsson G, Ross SB (1984) A parametric study of the AQ9 04 effects of the noradrenaline neurotoxin DSP4 on avoidance 505

\begin{tabular}{|l|lll|}
\hline & Journal : Large 702 & Dispatch : 25-4-2014 & Pages : 13 \\
Article No. : $\mathbf{1 2 2 3}$ & $\square$ LE & $\square$ TYPESET \\
MS Code : JNT-D-13-00293 & $\sim_{\mathrm{CP}}$ & $\checkmark$ DISK \\
\hline
\end{tabular}


acquisition and noradrenaline neurones in the CNS of the rat. Br J Pharmacol 82:249-257

Arimoto T, Bing G (2003) Up-regulation of inducible nitric oxide synthase in the substantia nigra by lipopolysaccharide causes microglial activation and neurodegeneration. Neurobiol Dis 12:35-45

Bing G, Zhang Y, Watanabe Y, McEwen BS, Stone EA (1994) Locus coeruleus lesions potentiate neurotoxic effects of MPTP in dopaminergic neurons of the substantia nigra. Brain Res 668:261-265

Braak H, Del Tredici K, Rub U, de Vos RA, Jansen Steur EN, Braak E (2003) Staging of brain pathology related to sporadic Parkinson's disease. Neurobiol Aging 24:197-211

Bukhatwa S, Iravani MM, Zeng BY, Cooper JD, Rose S, Jenner P (2009) An immunohistochemical and stereological analysis of PSI-induced nigral neuronal degeneration in the rat. J Neurochem 109:52-59

Castano A, Herrera AJ, Cano J, Machado A (1998) Lipopolysaccharide intranigral injection induces inflammatory reaction and damage in nigrostriatal dopaminergic system. J Neurochem 70:1584-1592

Chang JY, Liu LZ (2000) Catecholamines inhibit microglial nitric oxide production. Brain Res Bull 52:525-530

de Meira Santos Lima M, Braga Reksidler A, Marques Zanata S, Bueno Machado H, Tufik S, Vital MA (2006) Different parkinsonism models produce a time-dependent induction of COX-2 in the substantia nigra of rats. Brain Res 1101:117-125

Del Tredici K, Rub U, De Vos RA, Bohl JR, Braak H (2002) Where does Parkinson disease pathology begin in the brain? J Neuropath Exp Neurol 61:413-426

Dudley MW, Howard BD, Cho AK (1990) The interaction of the beta-haloethyl benzylamines, xylamine, and DSP-4 with catecholaminergic neurons. Ann Rev Pharmacol Toxicol 30:387-403

Feinstein DL, Heneka MT, Gavrilyuk V, Dello Russo C, Weinberg G, Galea E (2002) Noradrenergic regulation of inflammatory gene expression in brain. Neurochem Int 41:357-365

Fornai F, Bassi L, Torracca MT, Alessandri MG, Scalori V, Corsini GU (1996) Region- and neurotransmitter-dependent species and strain differences in DSP-4-induced monoamine depletion in rodents. Neurodegeneration 5:241-249

Fornai F, Alessandri MG, Torracca MT, Bassi L, Corsini GU (1997) Effects of noradrenergic lesions on MPTP/MPP+ kinetics and MPTP - induced nigrostriatal dopamine depletions. J Pharmacol Exp Ther 283:100-107

Forno LS, DeLanney LE, Irwin I, Langston JW (1993) Similarities and differences between MPTP-induced parkinsonsim and Parkinson's disease. Neuropathologic considerations. Adv Neurol 60:600-608

Fritschy JM, Grzanna R (1991) Selective effects of DSP-4 on locus coeruleus axons: are there pharmacologically different types of noradrenergic axons in the central nervous system? Prog Brain Res 88:257-268

German DC, Manaye KF, White CL 3rd, Woodward DJ, McIntire DD, Smith WK, Kalaria RN, Mann DM (1992) Diseasespecific patterns of locus coeruleus cell loss. Ann Neurol 32:667-676

Grenhoff J, Nisell M, Ferre S, Aston-Jones G, Svensson TH (1993) Noradrenergic modulation of midbrain dopamine cell firing elicited by stimulation of the locus coeruleus in the rat. J Neural Trans 93:11-25

Heneka MT, Landreth GE (2007) PPARs in the brain. Biochim Biophys Acta 1771:1031-1045

Heneka MT, Gavrilyuk V, Landreth GE, O'Banion MK, Weinberg G, Feinstein DL (2003) Noradrenergic depletion increases inflammatory responses in brain: effects on Ikappa B and HSP70 expression. J Neurochem 85:387-398
Herrera AJ, Castano A, Venero JL, Cano J, Machado A (2000) The single intranigral injection of LPS as a new model for studying the selective effects of inflammatory reactions on dopaminergic system. Neurobiol Dis 7:429-447

Iravani MM, Kashefi K, Mander P, Rose S, Jenner P (2002) Involvement of inducible nitric oxide synthase in inflammation-induced dopaminergic neurodegeneration. Neuroscience 110:49-58

Iravani MM, Leung CC, Sadeghian M, Haddon CO, Rose S, Jenner P (2005) The acute and the long-term effects of nigral lipopolysaccharide administration on dopaminergic dysfunction and glial cell activation. Eur J Neurosci 22:317-330

Iravani MM, Haddon CO, Rose S, Jenner P (2006) 3-Nitrotyrosinedependent dopaminergic neurotoxicity following direct nigral administration of a peroxynitrite but not a nitric oxide donor. Brain Res 1067:256-262

Iravani MM, Sadeghian M, Leung CC, Tel BC, Rose S, Schapira AH, Jenner P (2008) Continuous subcutaneous infusion of pramipexole protects against lipopolysaccharide-induced dopaminergic cell death without affecting the inflammatory response. Exp Neurol 212:522-531

Iravani MM, Sadeghian M, Leung CC, Jenner P, Rose S (2012) Lipopolysaccharide-induced nigral inflammation leads to increased IL-1beta tissue content and expression of astrocytic glial cell line-derived neurotrophic factor. Neurosci Lett 510:138-142

Lavigne MC, Malech HL, Holland SM, Leto TL (2001) Genetic requirement of $\mathrm{p} 47 \mathrm{phox}$ for superoxide production by murine microglia. FASEB J 15:285-287

Marien M, Briley M, Colpaert F (1993) Noradrenaline depletion exacerbates MPTP-induced striatal dopamine loss in mice. Eur J Pharmacol 236:487-489

Mavridis M, Degryse AD, Lategan AJ, Marien MR, Colpaert FC (1991) Effects of locus coeruleus lesions on parkinsonian signs, striatal dopamine and substantia nigra cell loss after 1-methyl-4phenyl-1,2,3,6-tetrahydropyridine in monkeys: a possible role for the locus coeruleus in the progression of Parkinson's disease. Neuroscience 41:507-523

Nishi K, Kondo T, Narabayashi H (1991) Destruction of norepinephrine terminals in 1-methyl-4-phenyl-1,2,3,6-tetrahydropyridine (MPTP)-treated mice reduces locomotor activity induced by L-dopa. Neurosci Lett 123:244-247

O’Banion MK (1999) Cyclooxygenase-2: molecular biology, pharmacology, and neurobiology. Crit Rev Neurobiol 13:45-82

Paxinos G, Watson C (1986) The rat brain in stereotaxic coordinates. Academic Press, New York

Pugh PL, Vidgeon-Hart MP, Ashmeade T, Culbert AA, Seymour Z, Perren MJ, Joyce F, Bate ST, Babin A, Virley DJ, Richardson JC, Upton N, Sunter D (2007) Repeated administration of the noradrenergic neurotoxin $N$-(2-chloroethyl)- $N$-ethyl-2-bromobenzylamine (DSP-4) modulates neuroinflammation and amyloid plaque load in mice bearing amyloid precursor protein and presenilin-1 mutant transgenes. J Neuroinflammation 4:8

Rommelfanger KS, Weinshenker D, Miller GW (2004) Reduced MPTP toxicity in noradrenaline transporter knockout mice. J Neurochem 91:1116-1124

Schlachetzki JC, Fiebich BL, Haake E, de Oliveira AC, CandelarioJalil E, Heneka MT, Hull M (2010) Norepinephrine enhances the LPS-induced expression of COX-2 and secretion of PGE2 in primary rat microglia. J Neuroinflammation 7:2

Srinivasan J, Schmidt WJ (2003) Potentiation of parkinsonian symptoms by depletion of locus coeruleus noradrenaline in 6-hydroxydopamine-induced partial degeneration of substantia nigra in rats. Eur J Neurosci 17:2586-2592

Teismann P, Tieu K, Choi DK, Wu DC, Naini A, Hunot S, Vila M, Jackson-Lewis V, Przedborski S (2003) Cyclooxygenase-2 is 
instrumental in Parkinson's disease neurodegeneration. Proc Natl Acad Sci USA 100:5473-5478

Troadec JD, Marien M, Darios F, Hartmann A, Ruberg M, Colpaert F, Michel PP (2001) Noradrenaline provides long-term protection to dopaminergic neurons by reducing oxidative stress. J Neurochem 79:200-210

Zamanian JL, Xu L, Foo LC, Nouri L, Giffard RG, Barres BA (2012)

Genomic analysis reactive astrogliosis. J Neurosci 32:6392-6410
642

643

644

645

$\begin{array}{lll}\text { Journal : Large 702 } & \text { Dispatch : 25-4-2014 } & \text { Pages : 13 } \\ \text { Article No. : } \mathbf{1 2 2 3} & \square \text { LE } & \square \text { TYPESET } \\ \text { MS Code : JNT-D-13-00293 } & \sim_{\text {CP }} & \checkmark \text { DISK }\end{array}$




\section{Author Query Form}

Springer

the language of science

\section{Please ensure you fill out your response to the queries raised below and return this form along with your corrections}

\section{Dear Author}

During the process of typesetting your article, the following queries have arisen. Please check your typeset proof carefully against the queries listed below and mark the necessary changes either directly on the proof/online grid or in the 'Author's response' area provided below

\begin{tabular}{|l|l|l|}
\hline Query & Details Required & Author's Response \\
\hline AQ1 & Kindly check the article title is correctly processed or not. & $\begin{array}{l}\text { References del Tredici and Braak (2013) are cited in text but not provided in the reference list. Please } \\
\text { provide references in the list or delete these citations. }\end{array}$ \\
\hline AQ2 & Kindly check Heneka et al. (2007) changed as Heneka and Landreth (2007) is identified correctly & \\
\hline AQ3 & Kindly check Buthatwa et al. (2009) given in text and not in reference list & \\
\hline AQ4 & Kindly check the inserted figure citation 1 here is identified correctly & \\
\hline AQ6 & Kindly check the inserted figure citation 3 here is identified correctly & \\
\hline AQ7 & Kindly check the inserted figure citation 4 here is identified correctly & \\
\hline AQ8 & Please check and confirm the edit made to the sentence 'This is consistent with the presence of abundant & \\
\hline AQ9 & Reference Archer et al. (1984) given in list but not cited in text. Please cite in text or delete from list. & \\
\hline
\end{tabular}

